
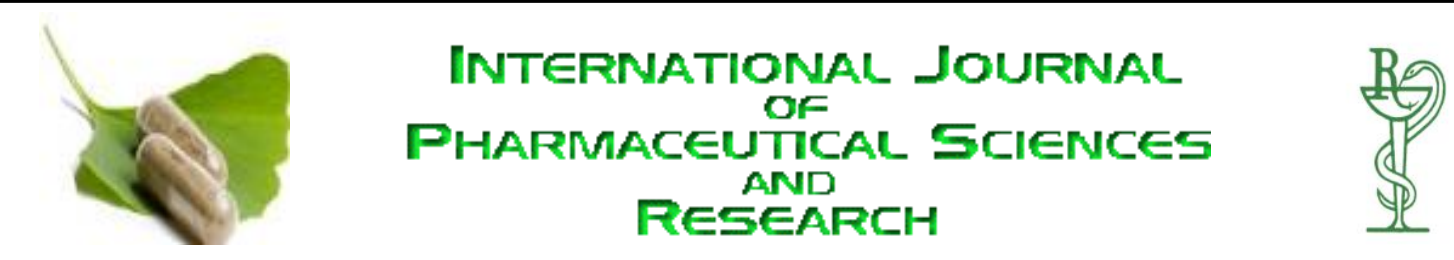

Received 04 January, 2010; received in revised form 22 January, 2010; accepted 27 January, 2010

\title{
MULTIPLE SCLEROSIS: A REVIEW
}

\author{
ASHWANI ARYA
}

Bharat Institute of Science, Tech. \& Management, Pehladpur, Kurukshetra (Haryana), India

\begin{abstract}
Keywords:

Multiple sclerosis,

Autoimmune disease,

Plaques,

Myelin,

White matter

*Correspondence for Author:

Ashwani Arya

Bharat Institute of Science, Tech. \& Management, Pehladpur, Kurukshetra.

E-mail:

ashwaniarya5@rediffmail.com

Mobile No- 09354999082

Multiple sclerosis affects around 2.5 million people worldwide it is one of the most common neurological disorders and cause of disability of young adults, especially in Europe and North America. There is a lack of epidemiological studies from Asia where the prevalence is reported to be low, though, with the availability of more neurologists and magnetic resonance imaging, a larger number of patients are being diagnosed. MS is a slowly progressive, immunologically mediated disease of the central nervous system, characterized by inflammation and demyelination of white matter in the brain and spinal cord. A triad of symptoms clinically characterize Multiple sclerosis: changes in sensation, muscle weakness, ataxia, dysarthria, dysphagia, visual problems, fatigue, acute or chronic pain, bladder and bowel difficulties. The diagnosis of MS is made on the basis of the clinical signs and symptoms, with magnetic resonance imaging (MRI) and other laboratory tests playing a supportive role. All tests are non specific and only provide supportive evidence for diagnosis. The effective management of multiple sclerosis is complex and draws on many disciplines, such as neurologists, physiotherapists, speech therapists, counsellors, general practitioners, nurses and pharmacists. There has been no specific treatment for multiple sclerosis so far. The therapies used to treat MS are targeted at different aspects of the disease and can be categorized into disease modifying therapies, treatments used in acute exacerbations and drugs used to treat disease complications.
\end{abstract}




\section{INTRODUCTION:}

Multiple sclerosis affects around 2.5 million people worldwide it is one of the most common neurological disorders and cause of disability of young adults, especially in Europe and North America. There is a lack of epidemiological studies from Asia where the prevalence is reported to be low, though, with the availability of more neurologists and magnetic resonance imaging, a larger number of patients are being diagnosed. Although some people experience little disability during lifetime, up to $60 \%$ are no longer fully ambulatory 20 years after onset, with significant implications for their quality of life and the finical cost to society ${ }^{1}$. Disease onset usually occurs in young adults, and it is more common in females ${ }^{2}$. The prevalence of MS is 1 per 1000 people and the ratio of female to male patients is 1.5 to 1 . MS has heterogeneous clinical presentations and courses, ranging from benign to classical relapsing remitting (RR; prevalence $45 \%)$, primary progressive (PP; prevalence $20 \%$ ) and secondary progressive (SP; prevalence $45 \%$ ) or rare fulminant disease courses ${ }^{3}$. MS was first described in 1868 by Jean-Martin Charcot ${ }^{4}$. Multiple sclerosis (MS) is an inflammatory demyelinating condition of central nervous system ( CNS) that is generally considered to be autoimmune in nature. In people with MS, the immune trigger is unknown, but the targets are myelinated CNS tracts. In regions of inflammation, break-down of blood-brain barrier occurs and destruction of myelin ensues, with axonal damage, gliosis and formation of sclerotic plaques ${ }^{1}$. MS is a slowly progressive, immunologically mediated disease of the central nervous system, characterized by inflammation and demyelination of white matter in the brain and spinal cord. The myelin sheath influences the rate of nerve impulse conduction with transmission being more rapid in myelinated nerve fibres. In MS the sheaths deteriorate to scleroses, which are hardened scars or plaques in multiple regions ${ }^{5}$. In MS, an autoimmune response is evoked that causes the body to attack its own myelin ${ }^{6}$. The disease is usually characterised by a relapsing remitting course in the early stages, with full or nearly full recovery initially. In the early stages there may be little damage to axons. Over time the disease enters an irreversible progressive phase of neurological deficit ${ }^{7}$. Acute relapses are caused by inflammatory demyelination ${ }^{8}$, while disease progression is thought to result from axonal loss $^{9}$. Each relapse causes further loss of nervous tissue and progressive dysfunction. In some cases there may be chronic progression without remission or acute disease rapidly leading to death ${ }^{9}$. There is no known cure for MS. Treatments attempt to return function after an attack, prevent new attacks, and prevent disability. The prognosis is difficult to predict; it depends on the subtype of the disease, the individual patient's disease characteristics, the initial symptoms and the degree of disability the person experiences as time advances.

\section{Clinical Signs and Symptoms}

The clinical signs and symptoms of multiple sclerosis depend on where the plaques are formed and differ greatly between patients. A triad of symptoms clinically characterize Multiple sclerosis: changes in sensation (hypoesthesia and paraesthesia), muscle weakness, muscle spasms, or difficulty in moving; difficulties with coordination and balance (ataxia); problems in speech (dysarthria) or swallowing (dysphagia), visual problems (nystagmus, optic neuritis, or diplopia), fatigue, acute or chronic pain, bladder and bowel difficulties ${ }^{2,10}$.Multiple sclerosis relapses are often unpredictable, occurring without warning and without obvious inciting factors with a rate rarely above $^{1}$ and a half per year ${ }^{2}$. Some attacks, however, are preceded by common triggers. 
Relapses occur more frequently during spring and summer. Viral infections such as the common cold, influenza, or gastroenteritis increase the risk of relapse ${ }^{2}$.

\section{Diagnosis of MS}

The diagnosis of MS is made on the basis of the clinical signs and symptoms, with magnetic resonance imaging (MRI) and other laboratory tests playing a supportive role. All tests are non specific and only provide supportive evidence for diagnosis.

\section{Laboratory tests in MS:}

\section{Magnetic resonance imaging (MRI)}

MRI is the single most useful laboratory test in the diagnosis of MS. In 1981, Young et al have com- pared MRI and CT scans in patients with MS. They demonstrated that MRI not only picked up all the lesions seen on the CT scan, it revealed many more, particularly in the brain stem. The lesions also had more distinct margins. All patients had multiple lesions on $\mathrm{MRI}$ and many of these were per ventricular and hence considered specific for MS by these authors ${ }^{11,12}$. In 1988, Isaac et al have demonstrated that MRI evidence for disease activity is much more frequent than clinical evidence $^{13}$.

\section{Electrophysiological tests}

i. Visual evoked potentials (VEP) are most frequently employed in clinical practice. Since MS affects anterior optic pathways, VEP reveal abnormality in significant number of patients. In the series of Halliday et al $86 \%$ patients of MS who had no history of ON and had normal optic disc showed an abnormal VEP ${ }^{14}$.

ii. Brainstem auditory evoked potentials (BAEP) have also been used in the diagnosis of MS. Sixty percent of patients without clinical signs of brainstem involvement showed abnormalities. of BAEP ${ }^{15}$.

\section{Other laboratory tests}

i. The examination of cerebrospinal fluid (CSF)

has been used to support the diagnosis of MS for a long time. The presence of myelin basic protein in the CSF of MS patient may be highly suggestive of activity of MS process but its absence does not rule out active disease ${ }^{16}$.

ii. Presence of IgG oligoclonal band in the CSF has proved to be the most sensitive laboratory test in the diagnosis of MS and is not dependent on the activity of the disease and treatment received by the patient.

\section{Classification of Multiple Sclerosis:}

MS is essentially divided into four main courses:

1-Relapsing-remitting MS:- Episodes of acute worsening of neurologic function, with some amount of recovery (the most common form) and no progression in between 2 . Approximately $80 \%$ of patients will initially present this form of MS, in which there are unpredictable attacks (relapses) during which new symptoms appear or existing symptoms become more severe. The relapses can last for varying period (day or month) and there is partial or total recovery / remission ${ }^{1,17}$.

Primary-progressive MS:- Continuing worsening of disease without distinct relapses ${ }^{1}$. This affects around $10-15 \%$ of all MS patients, is characterized by a lack of distinct attacks, but with slow onset and then stedily worsening symptoms? There is an accumulation of deficits and disability which may level off at some point or continue over years $^{1,18}$.

\section{Secondary-progressive MS:- Relapsing- remitting disease initially, eventually converting to a progressive form with a gradual loss of function. It is characterized by}


progression that is not relapse related ${ }^{2}$. Approximately $50 \%$ of patients with relapsing/ remitting MS will develop secondary progressive MS within 10 years, and $80 \%$ will have developed this form of MS within 20 years of disease onset ${ }^{1,19}$.

Progressive-relapsing: - Progressive disease from onset, with acute relapses and continuing disease progression ${ }^{1,2}$.

\section{Pathophysiological Features of Multiple Sclerosis:}

The pathological signature of $\mathrm{MS}$ is the white matter plaque, a circumscribed area of demyelination and relative axonal preservation. Plaques may occur anywhere within the white matter but favour the periventricular regions, optic nerves, brain stem, cerebellum, and spinal cord. Depending on their stage of development, they contain varying proportions of immune cells and immune reactive substances.

Multiple sclerosis (MS) is a disease in which the fatty myelin sheaths around the axons of the brain and spinal cord are damaged, leading to demyelination and scarring as well as a broad spectrum of signs and symptoms ${ }^{2,20}$. MS affects the ability of nerve cells in the brain and spinal cord to communicate with each other. Nerve cells communicate by sending electrical signals called action potentials down long fibers called axons, which are wrapped in an insulating substance called myelin. In MS, the body's own immune system attacks and damages the myelin. When myelin is lost, the axons can no longer effectively conduct signals. The name multiple sclerosis refers to scars (scleroses-better known as plaques or lesions) in the white matter of the brain and spinal cord, which is mainly composed of myelin ${ }^{20}$. Although much is known about the mechanisms involved in the disease process, the cause remains unknown. Theories include genetics or infections. Different environmental risk factors have also been found ${ }^{21}$.

Immune Dysfunction and Damage to CNS:-MS is characterized by the formation of multiple lesions along the nerve fibers in the brain and spinal cord. The key players include:

1- Axons, the nerve fibers that transmit information via electrical signals

2- Myelin, the fatty substance that wraps around the axons like an insulating sheath. Oligodendrocytes, the cells that make up the myelin

3- Blood vessels that supply oxygen and nutrients

4- Inflammatory factors, such as cytokines.

5- T-cells, a form of white blood cell presenting cells, which introduce the myelin antigen to the $T$ cell

MS is thought to be an autoimmune disease, but what triggers the immune system to attack the body is still unclear. During this immune response, cells that identify antigens are somehow triggered to interpret one of the components of myelin as foreign. When antigen presenting cells introduce the myelin antigen to the T cells, the T cells pass through the blood-brain barrier and mount an attack on the myelin, activating more $T$ cells and other immune cells in the process ${ }^{22}$. Other inflammatory factors, such as cytokines, are released, and the end result is an immunologic cascade that produces tissue damage, not only to the myelin sheath, but to the underlying axons as well. This "demyelination" makes the transmission of information via axons more difficult ultimately, there is interference with the conduction of nerve impulses from the sensory organs to the CNS and from the CNS to the muscles. Injury to the axons themselves, called "axonal damage," can be part of this destructive process even early in the disease 
and may result in permanent loss of neuronal transmission $^{23}$. At least initially, however, the process of MS is typically a waxing and waning one. Inflammatory episodes occur in the form of periodic acute attacks, and once the inflammation subsides ${ }^{24}$, impaired function is usually recovered either completely or partially. Reversal of inflammation or the process of "remyelination" can occur over and over, or, permanent damage may occur at any time ${ }^{25}$.

Possible Triggers: - While MS is almost certainly an autoimmune disease, the factor or factors that trigger an attack on the spinal cord and brain's white matter remain unknown. A number of hypotheses are being explored, one being the role of viruses. Peripheral blood antibody titers too many viruses are elevated in people with MS. These include varicella zoster, vaccinia, rubella, Epstein-Barr, human herpes virus 6 (HHV-6), and others. In some cases, virus-specific antibody is also detected in the cerebrospinal fluid, and recently some viruses, especially HHV-6, have been detected near the characteristic brain lesions of some persons with MS. The relevance of these findings to the pathophysiology of the disease remains to be determined ${ }^{26}$. Its causes and the factors that contribute to its heterogeneity are largely unknown, although it is likely a complex trait with genetic and environmental components. The disease affects about $0.1 \%$ of the population in temperate climates, some 250,000 to 350,000 people in the United States. It is a disease of young people (median age of onset is approximately 28 years) but is lifelong and is often disabling; $50 \%$ of patients require a cane to walk 15 years after disease onset $^{3}$

Environment and Genetics: - The cause of MS is not known. Epidemiological findings support both environmental and genetic hypotheses, and these forces likely interact to produce individual disease susceptibility and influence disease course. Several observations seemingly support environmental hypotheses. The prevalence of MS generally increases with distance from the equator, and apparent epidemics and clusters of MS have been reported. Migration (and age at migration) may modify the disease risk, and concordance rates in monozygotic twins do not exceed approximately $30 \%{ }^{27}$. Some consider these findings as supportive of an ecological or infectious hypothesis for MS susceptibility. It is unclear whether putative environmental factors are operative at the individual level (e.g., infectious, transmissible agents) or elevate the risk of the entire population (e.g., ecological factors, such as climate, soil conditions, or diet) ${ }^{28}$.Ecological case-control studies are often limited because exposures are usually similar amongst cases and controls. Isolation of infectious agents and/or serological evidence of greater exposure in MS cases compared to controls have been reported frequently over several decades. Recent reports implicate human herpes virus 6 (HHV-6) ${ }^{20,29}$ and Chlamydia pneumoniae ${ }^{30}$ as causative agents, but others have failed to confirm these observations ${ }^{31}$. To date, no single infectious agent has withstood the test of time. Genetic predisposition to MS has been established from the following evidence: familial aggregation unexplained by environmental factors ${ }^{32}$; much higher monozygotic than dizygotic twin concordance rate $(31 \% \text { versus } 5 \%)^{33}$; ethnic predisposition (eg, Northern Europeans) and protection (many groups, including North American Indians and Hutterites, despite living in regions with high MS prevalence); and association with human leukocyte antigen (HLA) DR2. The exact mode of inheritance is unknown but does not appear to be Mendelian or mitochondrial in nature. In general, the risk to a first-degree relative is approximately $1 \%$ to $4 \%$ (10-40 times the population risk), but this 
value may be substantially higher in pedigrees with multiple affected members.

The genes that contribute to MS 1 . susceptibility have not been identified. The HLA DR2 allele has been associated with MS in many populations ${ }^{32}$. Four entire human genome screens by linkage have been reported ${ }^{34,35}$. Although refinement of the original genome screens continues ${ }^{36}$, the most consistent evidence of a susceptibility locus appears to be the HLA region on chromosome 6. It seems unlikely that any other single genes contribute a significant risk. Genetic factors may also determine disease course and severity, but HLA polymorphisms are not significant contributors ${ }^{37}$. Polymorphisms in the interleukin-1b-receptor and interleukin$1 b$-receptor antagonist genes ${ }^{38}$, the apolipoprotein $E$ gene $^{39}$, and immunoglobulin Fc receptor genes ${ }^{40}$ have been associated with disease course. These associations require confirmation.

\section{Therapeutic management}

The effective management of multiple sclerosis is complex and draws on many disciplines, such as neurologists and allied health workers like physiotherapists, occupational and speech therapists, counsellors and social workers as well as consultants, general practitioners, nurses and pharmacists. There has been no specific treatment for multiple sclerosis so far. The therapies used to treat MS are targeted at different aspects of the disease and can be categorized into disease modifying therapies, treatments used in acute exacerbations and drugs used to treat disease complications.

Disease modifying therapies: - The most plausible theory concerning the cause of MS is that it is an abnormal, autoimmune response. Therefore, most drugs in this category set out to modify the immune system, either by stimulation or suppression.

Interferon- The interferon are naturally occurring amino acids and are cytokines. They are synthesised in response to viruses and act on other cells to prevent them becoming infected. Gamma interferon produced by $T$ cells is thought to activate macrophages which then destroy myelin directly and has been shown to exacerbate MS. Interferon alpha and beta are produced by many different cells, including macrophages, fibroblasts and endothelial cells. Interferon beta is known to have immune-modulatory effects ${ }^{41}$.

These include inhibition of leukocyte proliferation and antigen presentation, inhibition of T-cells migration across the blood brain barrier and modulation of cytokine production to produce antiinflammatory environment ${ }^{42}$ of the beta interferon's, $1 \mathrm{a}$ and 1b (IFNB-1a and IFNB1b) have been shown to be most beneficial in multiple sclerosis. IFNB-1a and IFNB -1b are similar in their biological activity and in vivo pharmacokinetics ${ }^{43}$. There are three preparations in use, Avonex, Rebif (interferon beta-1a) and Betaferon (interferon beta-1b). Avonex is given by intramuscular injection at a dose of $30 \mu \mathrm{g}(6$ million IU) once a week. Rebif is given subcutaneously at a dose of $22 \mu \mathrm{g}$ (6 million IU) three times a week. Betaferon is given subcutaneously at a dose of $0.25 \mathrm{mg}(8$ million IU) on alternate days. The most common adverse effect is a flu-like syndrome, which is prominent at the start of therapy and then wear off with continued treatment. NSAIDs are recommended prophylactically before each interferon dose to alleviate the symptoms. 
2. Glatiramer acetate (copolymer-1) It is a synthetic polypetide analogue of myelin basic protein. It was accidentally discovered during attempts to induce experimental allergic encephalomyelitis in animals (the animal model of MS). Its mode of action has not been defined, although it is thought to involve inhibition of lymphocyte migration (44) and suppression of T-cell activation ${ }^{45}$. It may exert its effect by competing with myelin basic protein and perhaps other myelin auto antigens for binding to MHC Class II molecules expressed on antigen presenting cells ${ }^{46}$. It is given daily at a dose of $20 \mathrm{mg}$ subcutaneously and is well tolerated with the most common adverse experience being injection site reaction. A two year study demonstrated a $29 \%$ reduction in relapse rate in patients with RRMS ${ }^{47,48}$.

3. Intravenous immunoglobulin (IgG) In a two-year randomised controlled trial, approximately 150 patients with RRMS showed a favourable effect on relapse rate in the treatment group who received intravenous immunoglobulin ${ }^{49}$.

4. Cytotoxic immuno-suppressants Immunosuppressant drugs such as cyclophosphamide, mofetil, mitozantrone $^{50}$, azathioprine ${ }^{51}$ and cyclosporin offer only modest benefits and in general, these benefits are outweighed by their side Effects ${ }^{52,53}$.

5. Low-dose methotrexate- Once weekly treatment of methotrexate at a low dose (7.5 mg) has been shown to slow significantly the progression of chronic progressive $\mathrm{MS}^{54}$.

\section{Cladribine Cladribine} chlorodeoxyadenosine) is a purine antimetabolite and its use in MS is controversial. Side effects included thrombocytopenia, bone marrow suppression and herpes zoster attacks ${ }^{55-56}$.

7. Linomide- Linomide (quinoline-3carboxamide) is a synthetic immunomodulator that acts by stimulating killer $\mathrm{T}$ cells. It also interferes with antigen presentation (57). Linomide (2-5 mg daily by mouth) has been shown to suppress disease activity in those with SPMS (58). However, phase III trials were prematurely stopped due to a higher than expected incidence of myocardial infarction in the linomide-treated group ${ }^{59}$.

8. Anti- $\alpha \mathbf{4}$ integrin (Antegren)- Antegren is a monoclonal antibody directed against 4 integrin, a cell adhesion molecule involved in immune cell migration. A trial of 72 patients with active RRMS or SPMS reported a significant reduction in the number of active lesions on MRI after short term treatment with intravenous antegren 60,61 . Further studies are underway.

\section{Treatments used in acute exacerbations}

Acute exacerbation in the neurological status of a patient with multiple sclerosis may be due to an episode of inflammatory demyelination (relapse). Inter-current infection (especially urinary tract infection), electrolyte imbalance, fever or drug intoxication. In a relapse, neurological deterioration normally occurs over several days and recovery takes weeks to months. Corticosteroids are useful in accelerating recovery from an acute exacerbation, but do not affect long - term disability ${ }^{62}$. Corticosteroids are now normally used in treating relapses and are thought to 2- act by reducing oedema and inflammation and consequently resolving conduction block. They 
help to speed the rate of recovery but do not affect the eventual degree of recovery ${ }^{63}$. No conclusion has been reached as to which steroid is definitely superior ${ }^{64-66}$. The most popular choice is intravenous methyl prednisolone ${ }^{67}$.

The beneficial action of corticosteroids in MS is probably two-fold, involving both their immunosuppressive and anti-inflammatory effects. In MS, corticosteroids reduce inflammation and oedema around the plaques, which lowers the pressure on the axons and allows better nerve impulse conduction. Corticosteroids also repair the damaged BBB by reducing inflammation and hence reducing the passage of white blood cells and other inflammatory mediators through to the CNS. Immunosuppressant action of corticosteroids may exacerbate the infection, which in some cases, may lead to septicaemia. Side effects include restlessness, anxiety and insomnia. Depression psychosis or euphoria may also arise.

Oral steroids: - Oral prednisolone may be effective in shortening acute attacks of MS and tends to be used in the community in preference to intravenous steroids when relapses are not severe ${ }^{68,69}$.

Plasma exchange: - Therapeutic plasma exchange has been shown to benefit patients with severe relapses that have not responded to intravenous corticosteroids ${ }^{70}$.

Involvement of blood brain barrier in MS: The BBB is a feature of the blood capillaries found in the CNS. Historically, it has been known that MS is caused by certain white blood cells attacking the myelin surrounding the nerve cells of a person's own central nervous system ${ }^{71}$. Under normal condition BBB provides an effective separation between the blood cells and the myelin, such that the white blood cells should not have access in order to attack the myelin surrounding the nerve cells.
White blood cells also release matrix metalloproteinases (MMPs) which are activated by exposure to other enzymes ${ }^{71}$ weakening the intercellular cement.

There is another process which also has the potential to attack BBB integrity when white blood cells destroy invading organisms, superoxide and free radicals are released which are extremely active and can destroy many of the tissues they contact. However, when the process takes place at the BBB, it can be one more attack on the integrity of the barrier. A simple potential treatment for multiple sclerosis will be the strengthening of the BBB to the extent that no further breakdowns occur. Anthocyanosides, proanthocyanidins and procyanidolic oligomers have been found effective in strengthening the BBB in animals ${ }^{72}$.

Neurorehabilitation: - The Philosophy of Neurorehabilitation, which emphasizes patient education and self -management, is well suited to meet the complex and variable needs of $\mathrm{MS}^{73}$. Neurologists will be the main physicians involved, but depending on the symptom, doctors of other medical specialties may also be helpful. Allied treatments such as physiotherapy ${ }^{72}$, speech and language therapy ${ }^{74}$ or occupational therapy ${ }^{75}$ can also help to manage some symptoms and maintain quality of life.

Multidisciplinary approaches have been shown to be effective in increasing activity levels and participation in multiple sclerosis $^{76}$. Due to the paucity of randomized controlled studies, there is limited evidence of the overall efficacy of individual therapy disciplines, though there is good evidence that specific approaches, such as exercise ${ }^{77}$,psychology therapies, particularly cognitive behavioural approaches and energy conservation instruction are effective ${ }^{78}$. 


\section{Concluding Remarks:}

Multiple sclerosis (MS) is the most important human inflammatory demyelinating disease characterized by recurrent neurological relapses and/or progression that occur from multifocal white matter and cortical lesions within the central nervous system (CNS). MS is a chronic, progressive and essentially incurable disease that most often affects young adults. It is thought to be an autoimmune disease that affects the central nervous system. The course of MS is unpredictable and variable on a day-to-day and an individual patient basis. As chronic problems accumulate, the disease may become more steadily progressive, with fewer or no acute relapses.

A diagnosis of $\mathrm{MS}$ is a clinical one based on a thorough history and neurologic examination, and supported by MRI and other diagnostic tests. Management strategies fall into three general categories: acute treatment of relapses, prevention of progression or reduction in the frequency of relapses. The search for new drug treatment for MS is gaining momentum and the future looks brighter, although a cure for MS is still some way off.

\section{REFERENCES}

1. WHO. Neurological disorders: public health challenges 2006; 85-94.

2. Compstom A and Coles A: Multiple sclerosis. Lancet 2008; 372: 1502-17.

3. Rosati G : The prevalence of multiple sclerosis in the world : an update. Neurol. Sci 2001; 22(2): 117-39.

4. Berrios G E and Quemada JI: Multiple Sclerosis. The history of clinical Psychiatry 1995; 174-192.

5. Tortora GJ and Grabowski SR: Principles of Anatomy and Physiology. New York: Harper Collins College publisher. 7 Edition 1993;. 439.

6. Costello E: Exercise prescription for individuals with multiple sclerosis. Neurology Report 1996; 20:24-30.

7. Weinshenker $\mathrm{BH}$ : The natural history of multiple sclerosis: up date. Semin Neurol 1998; 18:301-307.

8. Lucchinetti, CF, Bruck, W, Rodriguez and Mand Lassmann $\mathrm{H}$ : Distinct patterns of multiple sclerosis pathology indicates heterogeneity on pathogenesis. Brain Pathol 1996; 6 : 259-74.

9. Trapp, BD, Peterson J, Ransohoff RM, Rudick R and Mork S: Axonal transection in the lesions of multiple sclerosis. N Engl J Med 1998; 338: 278-85.

10. Lublin FD and Reingold SC: Defining the clinical course of multiple sclerosis- results of an international survey. National Multiple Sclerosis Society (USA) Advisory Committee on Clinical Trials of New Agents in Multiple Sclerosis. Neurology 1996; 46 (4): 907-11

11. Poser $\mathrm{CM}$ and Brinar VV: Diagnostic criteria for multiple sclerosis: an historical review. Clin Neurol Neurosurg 2004; 106 (3): 147-58.

12. Young IR, Pallis CA, Budder GM, Legg NJ and Steiner RE: Nuclear magnetic resonance imaging of the brain in multiple sclerosis. Lancet 1981; 2:1063-6.

13. Isaac C, Genton M, Jardine C, Grochowski E and Palmer M: Multiple sclerosis: a serial study using MRI in relapsing patients. Neurology 1988; 38:15115.

14. Halliday AM, Mc Donald WI and Mushin H : Visual evoked response in diagnosis of multiple sclerosis. $\mathrm{Br}$ Med J 1973; 4:661-664.

15. Chiappa KH, Harrison JL, Brooks EB, and Young RR: Brainstem auditory evoked responses in 200 patients with MS. Ann Neurol 1980; 7:135-43.

16. Tourtellote WW and Walsh MJ: Cerebrospinal fluid profile in multiple sclerosis. New York: Thieme Stratton Inc 1984: 65-78.

17. Lublin FD and Reingold SC: Defining the clinical course of multiple sclerosis: results of and international study. Neurology 1996; 46: 907-911.

18. Miller DH and Leary SM: Primary-progressive multiple sclerosis. Lancet Neurol 2007;6(10):903-12.

19. Rovaris M, Confavreux C, Furlan R, Kappos L, Comi G and Filippi $M$ : Secondary progressive multiple sclerosis current knowledge and future challenges. Lancet Neurol 2006; 5 (4): 343-54.

20. Compston A and Coles A: Multiple sclerosis. Lancet 2002; 359 (9313): 1221-31.

21. Ascherio $A$ and Munger KL: Environmental risk factors for multiple sclerosis. Part I- the role of infection. Ann. Neurol 2007; 61 (4): 288-99.

22. Krishnamoorthy G, Saxena A, Mars LT, Domingues HS and Wekerle $\mathrm{H}$ : Myelin-specific $\mathrm{T}$ cells also recognize neuronal autoantigen in a transgenic mouse model of multiple sclerosis . Nat. Med. 2009; 15 (6): 626-32.

23. Pascual AM, Martínez-Bisbal MC and Boscá I: Axonal loss is progressive and partly dissociated from lesion load in early multiple sclerosis. Neurology 69 2007; (1): 63-7.

24. Lucchinetti C, Brück W, Parisi J, Scheithauer B, Rodriguez $\mathrm{M}$ and Lassmann $\mathrm{H}$ : Heterogeneity of multiple sclerosis lesions: implications for the 
pathogenesis of demyelination. Ann. Neurol. 2000; 47 (6): 707-17.

25. Chari DM : Remyelination in multiple sclerosis. Int. Rev. Neurobiol 2007; 79: 589-620.

26. Sotelo J, Martínez-Palomo A, Ordoñez G and Pineda B: Varicella-zoster virus in cerebrospinal fluid at relapses of multiple sclerosis. Ann. Neurol 2008; 63 (3): 303-311.

27. Mumford CJ, Wood NW, Kellar-Wood H, Thorpe J, Miller D, and Compston DAS: The British Isles survey of multiple sclerosis in twins. Neurology 2004; 44:1115.

28. Lauer K: Ecologic studies of multiple sclerosis. Neurology 1997; 49(2):18-26.

29. Friedman JE, Lyons MJ, Ablashl DV, Whitman JE, Edgar M, Koskiniemi M, Vaheri A and Zabriskie JB: The association of the human herpesvirus- 6 and MS. Mult Scler 1999; 5:355-362.

30. Gilden DH: Chlamydia: a role for multiple sclerosis or more confusion? Ann Neurol 1999; 46:4-5.

31. Boman J, Roblin PM, Sundstrom P, Sandstrom M, and Hammerschlag MR : Failure to detect Chlamydia pneumoniae in the central nervous system of patients with MS. Neurology 2000; 54:265-270.

32. Ebers GC, Sadovnick AD, and Risch NJ: A genetic basis for familial aggregation in multiple sclerosis. Canadian Collaborative Study Group. Nature 1995; 377:150-151.

33. Sadovnick AD, Armstrong $H$, Rice GPA, Bulman D, Hashimoto L and Murray TJ: A population-based study of multiple sclerosis in twins: Update. Ann Neurol 1993; 33:281-285.

34. Sawcer S, Jones HB, Feakes R, Gray J, Smaldon N, Chataway and Compston A : A genome screen in multiple sclerosis reveals susceptibility loci on chromosome 6 p21 and 17q22. Nat Genet 1996; 13:464-468.

35. Dyment DA, Ebers GC and Sadovnick AD: Genetics of multiple sclerosis. Lancet Neurol 2004; 3 (92): 10410.

36. Chataway J, Feakes R, Coraddu F, Gray J, Deans J, Fraser $\mathrm{M}$, Robertson $\mathrm{N}$ and Compston $\mathrm{A}$ : The genetics of multiple sclerosis: principles, background and updated results of the United Kingdom systematic genome screen. Brain 1998; 121:1869-1887.

37. Weinshenker BG, Santrach P, Bissonet AS, Mcdonnell SK and Schaid D : Major histocompatibility complex class II alleles and the course and outcome of MS- A population-based study. Neurology 1998; 51: 742747.

38. Schrijver HM, Crusius JB, Uitdehaag BM, Garcia Gonzalez MA, Kostense PJ, Polman $\mathrm{CH}$, and Pena AS : Association of interleukin-1 beta and interleukin-1 receptor antagonist genes with disease severity in MS. Neurology 1999; 52:595- 599.
39. Evangelou N, Jackson $M$, Beeson and Palace J: Association of the APOE epsilon4 allele with disease activity in multiple sclerosis. J Neurol Neurosurg Psychiatry 1999; 67:203- 205.

40. Myrh KM, Raknes $G$, Nyland $H$ and Vedeler C: Immunoglobulin G Fc-receptor (Fc g R) IIA and IIIB polymorphisms related to disability in MS. Neurology 1999; 52:1771-1776.

41. Weinstock-Guttman B, Ransohoff RM, Kinkel RP and Rudick RA: The interferons: biological effects, mechanisms of action, and use in multiple sclerosis. Ann Neurol 1995; 37:7- 15.

42. Yong VW, Chabot S and Stuve O, Williams G: Interferon beta in the treatment of multiple sclerosis-mechanisms of action. Neurology 1998; 51:682-689

43. The IFNB multiple sclerosis study group: Interferon beta- $1 \mathrm{~b}$ is effective in relapsing-remitting multiple sclerosis: Clinical results at a multicentre, randomised, double-blind, placebo- controlled trial. Neurology 1993; 43:655-650.

44. Prat A, Al-Asmi A, Duquette $P$ and Antel JP: Lymphocyte migration and multiple sclerosis: Relation with disease course and therapy. Ann Neurol 1999; 46:253-256.

45. Miller A, Shapiro S, Gershtein R, Kinarty A, Rawashdeh $\mathrm{H}$ and Honigman $\mathrm{S}$ : Treatment of multiple sclerosis with copaxone: implicating mechanisms of Th1 to Th2/Th3 immune- deviation. J Neuroimmunol 1998; 92:113-21.

46. Arnon R, Sela M and Teitelbaum B: New insights in to the mechanism of action of copolymer 1 reduces relapse rate and improves disability in relapsingremitting multiple sclerosis: results of a phase III multicenter, double-blind, placebo- controlled trial. Neurology 1995; 45:1268-76.

47. Johnson KP, Brooks BR, Cohen JA, Ford CC, Goldstein $J$ and Lisak RP: Copolymer 1 reduces relapse rate and improves disability in relapsing-remitting multiple sclerosis- results of a phase III multicenter, doubleblind, placebo-controlled trial. Neurology 1995; 45:1268-76.

48. Johnson KP, Brooks BR, Cohen JA. Ford CC, Goldstein $\mathrm{J}$ and Lisak RP: Extended use of glatiramer acetate is well tolerated and maintains its clinical effect on multiple sclerosis relapse rate and degree of disability. Neurology 1998;50: 701-708.

49. Fazekas F, Deisenhammer F, Strasser FS, Nahler G and Mamoli B: Randomised placebo-controlled trial of monthly intravenous-immunoglobulin therapy in relapsing-remitting multiple sclerosis. Lancet 1997; 349:589-93.

50. Millefiorini E, Gasperini C, Pozzilli C, D’ Andrea F, Bastianello $S$ and Trojano $\mathrm{M}$ : Randomised placebo controlled trial of mitozantrone in relapsing - 
remitting multiple sclerosis. J Neurol 1997; 244:153159.

51. Yudkin PL, Ellison GW, Ghezzi A, Goodkin DE, Hughes RA and Mc Pherson K: Overview of azathioprine treatment in multiple sclerosis. Lancet 1991; 338:1051-55.

52. Hauser SL: Intensive immunosuppression in progressive multiple sclerosis: a randomised, three arm study of high dose cyclophosphamide, plasma exchange and ACTH. N Engl J Med 1983; 308:173-80.

53. British and Dutch MS Azathioprine Trial Group. Doublemasked trial of azathioprine in multiple sclerosis. Lancet 1988; 2:179-180.

54. Goodkin DE, Rudick RA, Vander Burg Medendorp S, Ddaughtry MM, Schwetz KM, and Fischer J: Lowdose oral methotrexate reduces the rate of progression in chronic progressive multiple sclerosis. Ann Neurol 1995; 37:30-40.

55. Sipe JC, Romine JS, Koziol JA, Mc Millian R, Zyroff J and Beutler $\mathrm{E}$ : Cladribine in treatment of chronic progressive multiple sclerosis. Lancet 1994; 344:9-13.

56. Romine JS, Sipe JC, Koziol JA, Zyroff J and Beutler E: A double blind, placebo-controlled, randomised trial of cladribine in relapsing-remitting multiple sclerosis. Proc Assoc Am Phys 1999; 111:35-44.

57. Polman $\mathrm{CH}$ and Hartung $\mathrm{H}$ : The treatment of multiple sclerosis: current and future. Curr Opin Neurol 1995; 8:200-9.

58. Karussi D, Meiner Z, Lehmann D, Gomori JM, Schwarz $A$ and Linde A: Treatment of secondary progressive multiple sclerosis with the immunomodulator linomide: a double - blind, placebo-controlled pilot study with monthly MRI evaluation. Neurology 1996; 47:341-6.

59. Tremlett $\mathrm{H}$ and Luscombe DK: Multiple sclerosis. Pharmaceutical J 1998; 260:29-38.

60. Tubridy N, Behan PO, Capildeo R, Chaudhuri A, Forbes $\mathrm{R}$ and Hawkins $\mathrm{CP}$ : The effect of anti-alpha 4 integrin antibody on brain lesion activity in MS. Neurology 1999; 53:466-72.

61. Johnson KP: Control of multiple sclerosis relapses with immunomodulating agents. J. Neurol. Sci. 2007 ; 256 (1): 23-28.

62. Sibley WA: Therapeutic claims in multiple sclerosis. New York: Demosvermande, $4^{\text {th }}$ Edition. 1996

63. Milligan NM, New combe R and Compston DA: A double blind controlled trial of high dose methyl prednisolone in patients with multiple sclerosis. J Neurol Neurosurg Psych 1987; 50: 511-516.

64. Beck RW: The opticneuritis treatment trial: threeyear follow- up results. Arch Opthalmol 1995; 113:136-7.

65. Alam SM, Kyriakides T, Lawden and Neuman PK: Methyl prednisolone in multiple sclerosis: a comparison of oral with intravenous therapy at equivalent high dose. J Neurol Neurosurg Psych 1993; 56:1219-20.

66. Barnes D, Hughes RA, Morris RW, Wade JO, Brown P and Britton $\mathrm{T}$ : Rondomised trial of oral and intravenous methylprednisolone in acute relapses of multiple sclerosis. Lancet 1997; 349:902-6.

67. Tremlett HL, Luscombe DK and Wiles CM: Use of corticosteroids in multiple sclerosis by consultant neurologists in the United Kingdom. J Neurol Neurosurg Psych 1998; 65: 362-5.

68. La Mantia L, Eoli M, Milanese C, Salmaggi A, Dufour A and Torri V: Double - blind trial of dexamethasone versus methyl prednisolone in multiple sclerosis acute relapses. Eur Neurol 1994; 34:199-203.

69. Milanese C, La Mantia L, Salmaggi A, Campi A, Eoli M and Scaioli V: Double - blind randomized trial of ACTH versus dexamethasone versus methyl prednisolone in multiple sclerosis bouts. Eur Neurol 1989; 29:10-4.

70. Weinshenker BG, O' Brien PC, Petterson TM, Noseworthy JH, Lucchinetti CF and Dodick DW: A randomised trial of plasma exchange in acute central nervous system inflammatory demyelinating disease. Ann Neurol 1999; 46:878-86.

71. Maeda A and Sobel RA: Matrix metalloproteinases in the normal human CNS, microglial nodules and multiple sclerosis lesions. J Neuropathol Exp Neuro 1996; 55: 300-9.

72. Monboisse JC, Braquet $P$, Randoux $A$ and Borel JP: Nonenzymatic degradation of acid soluble calf-skin collagen by superoxide ion: protective effect of flavonoids. Biochem Pharmacol 1983; 32: 53-8.

73. Thompson AJ: Neurorehabilitation in multilple sclerosis: foundations, facts and fiction. Current Opinion in Neurology 2005, 18: 267-271.

74. Ghaffar $O$ and Feinstein A: The neuropsychiatry of multiple sclerosis- a review of recent developments. Curr Opin Psychiatry 2007; 20 (3): 278-285.

75. Benedict $\mathrm{RH}$ and Bobholz JH: Multiple sclerosis. Seminars in neurology 2007; 27 (1): 78-85.

76. Steultjens EM, Dekker J, Bouter LM, Leemrijse CJ and van den Ende $\mathrm{CH}$ : Evidence of the efficacy of occupational therapy in different conditions- an overview of systematic reviews. Clinical rehabilitation 2005; 19 (3): 247-54.

77. Kurtzke JF: Rating neurologic impairment in multiple sclerosis an expanded disability status scale (EDSS). Neurology 1983; 33 (11): 144-52. 